the house-surgeon, were performed with promptness.

Five days have now elapsed, and I understand that the man has had not one unpleasant symptom; he has slept well; there has been no tension of the abdomen, the wound exhibits a mere line, the tumour sinks, and the limb is of a comfortable temperature. This case is the second of the kind which has occurred in the house.

Mr. Smith has been surgeon to the institution for nearly forty years.

May 26th, 1833.

\section{ANTI-HEMORRHAGIC EFFECTS OF THE} ERGOT OF RYE ON THE MALE.

\section{To the Editor of The Lancet.}

SIn,-I perceive in No. 502 of The LANcet, an article headed as above. In corroboration of the statement there put forward, $I$ beg to inform you, that I have employed that medicine with the same view for the last two years, with invariable success, my treatment being only somewhat more active than Dr. Lanyon's, viz., ten grains every second hour, in ordinary cases; but where the hemorrhage was very alarming, every hour for six or eight hours consecutively.

It is but just to state, that my adoption of this practice arose from reading an article on the same subject published in a Number of your truly invaluable journal, somewhen in the year 1831 .

I am, Sir, your most obedient,

HeNRY Augustus O'Slea.

May 4th, 1833 .

Surgenn, Aghada Dispensary, Cloyne.

$+$

Ergot of RYE,--Patient æt. 60.-Mr. Bright, surgeon, of Brighton, has forwarded to us a short paper on the powers of the ergot of rye in difficult labours and uterine hemorrhage. These are so fully admitted in the profession, that they do not need farther eulogy.

We extract, however, the following paragraph, which the age of the patient makes more interesting:- "I was sent for in haste to a poor woman, who was said to be bleeding to death. The case, on my entering the room, seemed to justify the report. The woman said her age was sixty, and that about six years since she ceased to menstruate. About a twelvemonth ago, she again became ' unwell,' and had so continued up to the present time. I found her literally bathed in blood, and immediately commenced with half-drachm doses of the secale cornutum: the following morning I saw her, found that all hemorrhage had ceased, and that she was still under the influence of the drug, which she described as producing pains like labour. She has been perfectly well up to the present date."

Malignant Cholera.-Case of Mr. John Stephenson.- - To the communication from Dr. Weatherill, inserted in another part of the Journal, the following note was appended] :- " This case is mentioned in No. 470 of ThE LANCET. Into the veins of this person $I$ injected, in the space of thirteen hours, four hundred and eighty ounces of saline fluid, in the collapsed stage of the cholera, with success; but as the report was sent for publication before the patient had perfectly recovered, I think it necessary now further to state, that he got rapidly well, and has ever since enjoyed the best of health.-J. W."

"Liverpool, June 6, 1833."

\section{NOTE FROM MR. WILLIAMS}

\section{To the Editor of The LANCET.}

Sir,-On perusing your "Notices to Correspond. ents" last Saturday, $f$ was not a little surprised to observe it stated that I was the author of certain questions put by a medical examiner to his pupil, pablished in THE LANcer of the preceding week. As I have never aspired to the unthankful, though perbaps to some the important, office of grinder, 1 must request the insertion in your next Number of this contradiction to that which appears to me to have been an intertional falsehood on the part of your informant. I am, Sir, your obedient servant, J. WIILIAMS,

A pothecary to the Lundon Hospital.

[We yive immediate insertion to $\mathrm{Mr}$. Williams" note, but have not yet had time since its receipt to demand an ex planation from our informant.-Ev.L.]

Mr. George Graham is requested to call at our office.

The 2nd Fasciculus of Dr. Carswell's splendid work on Pathological Anatomy has just been published.

Z. $Z$. Z. The "Testimonials" of Mr. M. have been weighed in the balance.-The letters of $M r, B, G, W$, and Veritas have been received.The theory of $A . S$. is ingenious, but there is an "if "inthe tirst proposition.-Mr.D. The announcenent of Rayer was made by us a month since.Or.J.C.W. What was the object of the nquiries? The correspondence reached us too late for this week's Number.

The letter of Mr. ********, who wished his article to appear with an aronymous signatule, did not reach us with his desire until after the article was published, as he is now probably aware. The B. is not connected with this office. The editor will be happy to receive early unformation on " medical atlairs of interest," on every opportunity that may offer.

$W . H$. The report is an invention. We never either saw or communicated with sir Wl. liam in our life. 